\title{
Prevalence of Asymptomatic Bacteriuria in HIV Infected Patients in a Tertiary Hospital in Lagos, Nigeria*
}

\author{
Akinsegun Akinbami $^{1 \#}$, Ibidun Bode-Shojobi ${ }^{2}$, Sarah Ajibola ${ }^{3}$, Olajumoke Oshinaike ${ }^{4}$, \\ Adewumi Adediran $^{5}$, Olaitan Ojelabi ${ }^{4}$, Kamal Ismail ${ }^{6}$, Bodunrin Osikomaiya ${ }^{6}$ \\ ${ }^{1}$ Department of Haematology and Blood Transfusion, College of Medicine, Lagos State University, Ikeja, Nigeria; ${ }^{2}$ Department of \\ Medical Microbiology, Lagos University Teaching Hospital, Idiaraba, Nigeria; ${ }^{3}$ Department of Haematology and Blood Transfusion, \\ Lagos University Teaching Hospital, Idiaraba, Nigeria; ${ }^{4}$ Department of Medicine, College of Medicine, Lagos State University, Ikeja, \\ Nigeria; ${ }^{5}$ Department of Haematology and Blood Transfusion, Faculty of Clinical Sciences, College of Medicine, University of La- \\ gos, Lagos, Nigeria; ${ }^{6}$ Department of Haematology and Blood Transfusion, Lagos State University, Teaching Hospital, Ikeja, Nigeria. \\ Email: \#ajoke_clinic@yahoo.co.uk
}

Received February $9^{\text {th }}, 2013$; revised March $11^{\text {th }}, 2013$; accepted March $18^{\text {th }}, 2013$

Copyright (C) 2013 Akinsegun Akinbami et al. This is an open access article distributed under the Creative Commons Attribution License, which permits unrestricted use, distribution, and reproduction in any medium, provided the original work is properly cited.

\begin{abstract}
Background: People living with Human Immunodeficiency Virus (HIV) are more predisposed to urinary tract infections due to suppression of their immunity by the virus. Asymptomatic bacteriuria is associated with an increased risk of symptomatic urinary tract infection and the latter being an important contributor to development of chronic renal failure, hypertension and toxaemia of pregnancy. The aim of this study was to determine the prevalence of asymptomatic bacteriuria in HIV-infected patients and proffer a recommendation on the need or otherwise to screen. Methods: This was a cross sectional study of treatment-naive HIV-infected patients attending the HIV clinics of Lagos State University Teaching Hospital (LASUTH), Ikeja. A single voided aseptically collected mid-stream urine (MSU) was obtained from each patient and all samples processed immediately, were sent for urinalysis and culture. Isolates were considered significant if there were $\geq 10^{5}$ colony forming unit $/ \mathrm{mL}(\mathrm{CFU} / \mathrm{mL})$ with 2 or less isolates, doubtful significance if $<10^{5}$ $\mathrm{CFU} / \mathrm{mL}$. Significant isolates were selected for identification. Data were analyzed using SPSS version 16.0 (Statistical Package for Social Sciences, Inc., Chicago, Ill). Results: A total of 156 consenting participants were recruited into the study. The mean age was $36.45 \pm 8.65$ years. There were 60 of $156(38.4 \%)$ males and 96 of $156(61.56 \%)$ females. Only 33 of $156(21.2 \%)$ had significant bacteriuria, out of the 33 participants, $19(57.8 \%)$ were asymptomatic, while 14 of $33(42.4 \%)$ had significant growth but were symptomatic or on antibiotics. E. coli was isolated in 9 of $19(47.3 \%)$, followed by Staph aureus 4 of 19 (21.05\%). Conclusion: More than half of participants who had significant growth had asymptomatic bacteriuria, while one-fifth of all patients had significant growth. Considering this statistics, screening for or treatment of asymptomatic bacteriuria may be recommended in all HIV-infected patients.
\end{abstract}

Keywords: Prevalence; Screening; Asymptomatic Bacteriuria; HIV-Infected Patients

\section{Background}

"Asymptomatic bacteriuria," or asymptomatic urinary infection, is isolation of a specified quantitative count of bacteria in an appropriately collected urine specimen obtained from a person without symptoms or signs refer- able to urinary infection [1].

\subsection{Diagnosis of Asymptomatic Bacteriuria}

\subsubsection{Urine Culture}

The gold standard of diagnosing bacteriuria is urine cul-

\footnotetext{
"Authors' contribution: Dr. Akinbami A. A.: Conceptualized and designed the study. Did the data entry and analysis. Dr. Bode-Shojobi I.: Carried out laboratory analysis; Dr. Sarah Ajibola: Carried out literature search and revised manuscript before final submission; Dr. Olajumoke Oshinaike: Made substantial contributions to conception and design of the manuscript and revised before final submission; Dr. Adewumi Adediran: Was involved in the drafting of the manuscript and revised it critically for important intellectual content; Dr. Olaitan Ojelabi: Was involved in the drafting of the manuscript and revised it critically for important intellectual content; Dr. Kamal Ismail: Revised the manuscript critically for important intellectual content and gave final approval of the version to be published; Dr. Bodunrin Osikomaiya: Revised the manuscript critically for important intellectual content and gave final approval of the version to be published. Conflict of interest: No conflict of interest declared.

${ }^{\#}$ Corresponding author.
} 
ture [2]. Diagnosis is achieved by identifying the presence of usually greater than or equal to $10^{5}$ colonyforming units per millilitre $(\mathrm{CFU} / \mathrm{mL})$ of the same organism or multiple organisms in two consecutive voided urine specimens for asymptomatic women [3], or a single, "clean-catch", voided urine specimen with one bacterial species isolated in a quantitative count of $10^{5} \mathrm{CFU} / \mathrm{mL}$ in asymptomatic men. Also, a single catheterized urine specimen with one bacterial species isolated in a quantitative count of $10^{2} \mathrm{CFU} / \mathrm{mL}$ in women or men [3].

\subsubsection{Non Culture Urine Tests}

A urinary dipstick is an example of non culture urine test. A urine dipstick leukocyte esterase test showing pyuria has a sensitivity of $75 \%-96 \%$ and a specificity of $94 \%$ 98\% [4]. However, this test may be positive with other inflammatory conditions of the genitourinary tract e.g. vaginitis, hence it is non-specific.

Nitrite test has several limitations and therefore has a high false-negative rate. Importantly, the test is unable to diagnose bacteriuria with non-nitrite producing pathogens [5]. Both a delay between urine sample collection and testing, and insufficient time since the last void for bacteria to produce sufficient amount of nitrites to appear at detectable levels contribute to the high false-negative rate [6].

A higher specificity can be achieved by combining the leukocyte-esterase and nitrite test results, but the quantitative urine culture remains the optimal screening test [2].

\subsection{Mechanism Predisposing to Asymptomatic Bacteriuria}

The normal genitourinary tract is sterile, apart from the distal urethra. Asymptomatic bacteriuria occurs following ascension of bacteria after the adherence of uropathogens to the bladder mucosa, up the urethra into the bladder, sometimes with subsequent ascension to the kidneys. Bacteria isolated from the urine of patients with asymptomatic bacteriuria usually originate as colonizing flora of the gut, vagina, or periurethral area [7].

\subsection{Justification for Bacteriuria Screening in HIV-Infected Patients}

Asymptomatic bacteriuria is common, but the prevalence in populations varies widely with age, sex, sexual activity and the presence of genitourinary abnormalities [3]. Asymptomatic bacteriuria has been reported to be associated with an increased risk of symptomatic urinary tract infection particularly in the presence of pyuria [8]. While, uncomplicated urinary tract infections (UTIs) occur most often in young healthy adult women and are easy to treat, in other patient groups, UTIs can have a complicated course, are more difficult to treat and often recur. Complicated UTIs occur most commonly in some group of patients like age over 65 years, treatment with immunosuppressive drugs, the presence of human immunodeficiency virus-infection and diabetes mellitus (DM) [9, $10]$.

Indications for screening of asymptomatic subjects for bacteriuria in a particular group of patient should be considered if adverse outcomes like complicated UTI, renal hypertension and chronic kidney disease pose a problem and can be prevented by antimicrobial therapy [11]. The use of antimicrobial therapy in asymptomatic bacteriuria may also be associated with adverse outcomes, like antimicrobial resistance, adverse drug effects, and cost.

Screening of asymptomatic subjects for bacteriuria is not recommendable if the treatment is not beneficial. The questions that should be answered are whether asymptomatic bacteriuria is associated with adverse outcomes in a particular group of patients, and whether the interventions of screening and antimicrobial treatment improve these outcomes.

People living with Human Immunodeficiency Virus (HIV) are likely to be more predisposed to urinary tract infections due to the suppression of their immunity and women in this category tend to get them more often due to the nature of their anatomy [12-14]. The incidence of UTI is higher in HIV-infected than HIV seronegative individuals [15], it is also higher amongst HIV-infected with low CD4 counts [16].

The depressed immunity in HIV infection vis-a-vis its renal complications e.g. HIV associated nephropathy, pyel onephritis, acute and chronic kidney diseases, makes the intervention of screening asymptomatic bacteriuria in this group of patients and possibly antimicrobial treatment desirable.

\section{Methods}

\subsection{Study Population}

This was a cross sectional study of 156 treatmentnaive HIV-infected patients attending the HIV clinics of Lagos State University Teaching Hospital (LASUTH), Ikeja. During the study period between April 2012 and October 2012 all consenting treatment-naive HIV-infected patients who gave written and verbal informed consent and satisfied the study's inclusion criteria were recruited into the study. With the aid of a pre-tested structured questionnaire, data like the sociodemographic, and urinary tract infections symptoms i.e. dysuria, haematuria, frequency, nocturia, fever, urgency, abdominal pain, and hesitancy were collected from participants. Preentry CD4 counts of participants were retrieved from their folders. 


\subsection{Ethics}

The research was approved by the Ethics Review Committees of LASUTH.

\subsection{Inclusion Criteria}

Amongst the HIV-infected patients who gave informed consent, only those who were HAART-naive were enrolled.

\subsection{Exclusion Criteria}

HAART-experienced patients.

\subsection{Sample Collection}

A single voided aseptically collected mid-stream urine (MSU) were obtained from female and male patients and all samples sent on the same day to Microbiology department for urinalysis and culture.

\subsection{Laboratory Analysis}

Samples were processed immediately. Urinalysis was performed on aliquots of MSU specimen using Combi Uriscreen 10SL test strips. Bacterial culture was performed by streaking $0.001 \mathrm{~mL}$ of mid stream collected urine with a calibrated loop on 5\% sheep blood agar and Cysteine Lactose Electrolyte Deficient (CLED) agar plates. These agar plates were incubated at $35^{\circ} \mathrm{C} \pm 2{ }^{\circ} \mathrm{C}$ for 24 hours under aerobic conditions. Isolates were considered significant if there were $\geq 10^{5}$ colony forming unit $/ \mathrm{mL}$ (CFU/mL) with 2 or less isolates, doubtful significance if $<10^{5} \mathrm{CFU} / \mathrm{mL}$. Mixed growths, in any count, of more than two organisms were considered to be contaminated. Significant isolates were selected for identification. API 20E (BioMerieux) was used for identifying the Gram Negative bacilli while the morphology on plates and biochemical reactions were used in identifying the gram positive cocci.

\subsection{Statistical Analysis}

Data were analyzed using SPSS version 16.0 (Statistical Package for Social Sciences, Inc., Chicago, Ill). The descriptive data were given as means \pm standard deviation (SD). The Pearson chi squared test was used for analytic assessment and the differences were considered to be statistically significant when the $\mathrm{p}$ value obtained was $<0.05$.

\section{Results}

A total of 156 consenting participants were recruited into the study. The mean age was $36.45 \pm 8.65$ years and a range of 15 - 59 years. There were 60 of $156(38.4 \%)$ males and 96 of $156(61.56 \%)$ females. The mean CD4 count of participants was $368.08 \pm 267.182$ cells $/ \mu \mathrm{L}$ and a range of 10 - 1264 cells $/ \mu \mathrm{L}$ (Table 1).

Majority, 93 of 156 (59.6\%) were married, 38 of 156 $(24.4 \%)$ single, 9 of $156(5.8 \%)$ separated, 2 of 156 $(1.3 \%)$ divorced and 14 of $156(9 \%)$ widowed. Majority, 82 of $156(52.6 \%)$ had secondary education, followed by 53 of $156(34 \%)$ with tertiary education and 14 of 156 (9\%) primary, while 7 of $156(4.5 \%)$ were illiterate with no formal education (Table 1).

A total of 22 of $156(12.1 \%)$ had dysuria, while majority, 133 of $156(85.3 \%)$ had no dysuria, similarly 14 of $156(8.9 \%)$ gave a history of pus discharge from the genital tract, while 142 of $156(91 \%)$ had no pus discharge from the genital tract. Only 1 of $156(0.6 \%)$ had haematuria, while 53 of $156(33.9 \%)$ had fever in the past two weeks.

A total of 50 of $156(32 \%)$ were on antibiotics as at the time of the study, only 47 of $156(30.1 \%)$ were sexually active. Urinalysis showed (Table 2$)$ only $1(0.6 \%)$ was positive to blood, 14 of $156(8.97 \%)$ had pyuria, only 5 of $156(3.2 \%)$ tested positive to nitrite while $151(96.8 \%)$ tested negative. A total of 52 of $156(33.3 \%)$ tested positive to protein, while 104 of $156(66.7 \%)$ tested negative. Only 2 of $156(1.2 \%)$ tested positive to glucose while 154 of $156(98.7 \%)$ tested negative to glucose. Only 1 of $156(0.6 \%)$ tested positive to ketones, while 155 of 156 (99.4\%) tested negative. All participants $100 \%$ tested negative to bilirubin, while 11 of $156(7.1 \%)$ tested positive to urobilinogen, 145 of $156(92.9 \%)$ tested negative to urobilinogen (Table 2).

Table 1. The sociodemographic data.

\begin{tabular}{|c|c|c|c|}
\hline \multicolumn{4}{|l|}{ Parameters } \\
\hline & Minimum & Maximum & Mean \\
\hline & 15 & 59 & $36.45 \pm 8.65$ \\
\hline & 10 & 1264 & $368.08 \pm 267.18$ \\
\hline \multicolumn{4}{|l|}{ Gender } \\
\hline Males & \multicolumn{3}{|c|}{60 of $156(38.4 \%)$} \\
\hline Females & \multicolumn{3}{|c|}{96 of $156(61.56 \%)$} \\
\hline \multicolumn{4}{|l|}{ Marital status } \\
\hline Married & \multicolumn{3}{|c|}{93 of $156(59.6 \%)$} \\
\hline Single & \multicolumn{3}{|c|}{38 of $156(24.44 \%)$} \\
\hline Separated & \multicolumn{3}{|c|}{9 of $156(5.8 \%)$} \\
\hline Divorced & \multicolumn{3}{|c|}{2 of $156(1.3 \%)$} \\
\hline Widowed & \multicolumn{3}{|c|}{14 of $156(9 \%)$} \\
\hline \multicolumn{4}{|c|}{ Educational level } \\
\hline Primary & \multicolumn{3}{|c|}{14 of $156(9 \%)$} \\
\hline Secondary & \multicolumn{3}{|c|}{53 of $156(34 \%)$} \\
\hline Tertiary & \multicolumn{3}{|c|}{53 of $156(34 \%)$} \\
\hline No education & \multicolumn{3}{|c|}{7 of $156(4.5 \%)$} \\
\hline
\end{tabular}


Only 33 of $156(21.2 \%)$ had significant bacteriuria (Table 3), the growth consisted of Escherichia coli (E. coli), 14 of $33(42.42 \%)$, followed by Staph aureus 9 of $33(27.27 \%)$, then Klebsiella oxytoca, 3 of $33(9.09 \%)$, Enterobacter aerogenes, Klebsiella pneumonia, Staph mascexeal, mixed growth Staph saprophyticus and E. coli 1 of $33(3.03 \%)$ each, Enterococcus species 2 of 33 (6.06\%).

Out of the 33 participants who had significant bacteriuria, 19 of $33(57.8 \%)$ were asymptomatic (Table 3), i.e. had no dysuria, haematuria, fever, urgency, abdominal pain, hesitancy nor were on any antibiotics. While 14 of $33(42.4 \%)$ had growth but had either dysuria, fever, or were on antibiotics. A prevalence of $57.8 \%$ was therefore obtained. Out of the 19 who had asymptomatic bacteriuria, $18(94.73 \%)$ of them were females and only 1 $(5.26 \%)$ male, also out of the 19, E. coli was isolated in 9 $(47.3 \%)$ including the male patient, followed by Staph aureus 4 of 19 (21.05\%) (Table 3). Other isolates were Klebsiella oxyteca, Enterobacter aerogenes, enterococcus species and Staph mascexeal.

Cross tabulating the entry CD4 count with various bacteria growth did not reach a significant level. $p$ value $=0.753$.

Table 2. Urinalysis table.

\begin{tabular}{lcc}
\hline Parameters & Positive & Negative \\
\hline Blood & 1 of $156(0.6 \%)$ & 155 of $156(99.4 \%)$ \\
Pyuria & 14 of $156(8.9 \%)$ & 142 of $156(91.02 \%)$ \\
Nitrite & 5 of $156(3.2 \%)$ & 151 of $156(96.79 \%)$ \\
Protein & 52 of $156(33.3 \%)$ & 104 of $156(66.66 \%)$ \\
Glucose & 2 of $156(1.2 \%)$ & 154 of $156(98.7 \%)$ \\
Ketones & 1 of $156(0.6 \%)$ & 155 of $156(99.4 \%)$ \\
Bilirubin & Nil & 156 of $156(100 \%)$ \\
Urobilinogen & 11 of $156(7.05 \%)$ & 145 of $156(92.9 \%)$ \\
\hline
\end{tabular}

Table 3. The prevalence of bacteriuria and asymptomatic bacteriuria.

\begin{tabular}{cc}
\hline Significant growth & No significant growth \\
\hline 33 of $156(21.2 \%)$ & 123 of $156(78.84 \%)$ \\
Asymptomatic bacteriuria & Symptomatic bacteriuria \\
19 of $33(57.8 \%)$ & 14 of $33(42.4 \%)$ \\
Isolates in asymptomatic bacteriuria & \\
Staph aureus & 9 of $19(47.3 \%)$ \\
\hline
\end{tabular}

\section{Discussion}

Urinary tract infections (UTIs) are among the most prevalent infectious diseases with a substantial health and financial burden on society. Both hereditary and behaveioural factors like sexual intercourse and use of diaphragm $[17,18]$, determine risk of having any urinary infection and whether it will be symptomatic or not is determined by the virulence of the organism [19]. Several studies have consistently confirmed patients with asymptomatic bacteriuria are at increased risk of symptommatic urinary tract infection and the latter being an important contributor to development of chronic renal failure, hypertension and toxaemia of pregnancy [19,20]. A positive urine culture even without symptoms is therefore considered potentially harmful.

The presence of pyuria is an evidence of inflammation in the genitourinary tract and is not sufficient to diagnose bacteriuria and the presence or absence of pyuria does not differentiate symptomatic from asymptomatic urinary infection. A pyuria prevalence of $8.97 \%$ obtained in this study, fell short of most reported studies, a $32 \%$ prevalent amongst young women was reported by Hooton et al. [20], 30\% - 70\% amongst pregnant women [21] and 70\% of diabetic women [22] also, 90\% of haemodialysis patients [23].

Urinary tract infection is one of the numerous causes of proteinuria. Proteinuria prevalence of $33.3 \%$ was obtained in this study is similar to $29 \%$ obtained amongst HIV-infected in the US [24] and 39.2\% reported in Cameroun [25].

This study also reported a prevalence of $21.1 \%$ of the population had significant bacteriuria, while $57.8 \%$ of those with significant bacteriuria had asymptomatic bacteriuria, and this concurs with a Kenya study which reported a prevalence of significant bacteriuria to be $23 \%$. The proportions of HIV-positive and HIV-negative women with bacteriuria were similar, and bacteriuria did not vary with CD4+ count in HIV-infected women [26]. Similarly, Hoepelman et al. [10] reported $30 \%$ of HIV-infected men with a CD4+ count less than 200 per milliliter had bacteriuria compared with $11 \%$ of HIV-infected men with CD4+ counts of 200 to 500, and no HIV-infected men with CD4+ counts over 500. The explanation for the increased prevalence with declining CD4 counts is not known, it is probably due to depressed immunity at a declining CD4 counts.

The high prevalence of $57.8 \%$ reported in this study is at variance with De Pinto et al.'s [27] report who found asymptomatic bacteriuria in $6.6 \%$ of men with AIDS at hospital admission; $3.2 \%$ of HIV-infected men without AIDS; and $1.8 \%$ in outpatient, non-HIV-infected men aged 18 to 50 years. The low prevalence reported by De Pinto et al. could be due to the fact that the prevalence of 
asymptomatic bacteriuria is generally lower in men compared to women because of female anatomy $[12,13]$. One other limitation of this study was that only a single urine culture was used while in most other studies, this diagnosis required two or even three consecutive positive urine cultures. This could be responsible for the high prevalence of asymptomatic bacteriuria reported in the present study.

Ibadin et al. [28] revealed HIV/AIDS to be a predisposing factor for increased incidence of urinary tract infection in the young. The implication of urinary tract infection associated with HIV is the increased cost of care for HIV/AIDS patients. The prevalence of asymptomatic bacteriuria is also high in some other groups of patients, i.e. $100 \%$ in patients with long-term indwelling catheters [29], 50.2\% in patients with intermittent catheterization [29] and 15\% - 50\% in institutionalised elderly patients [30,31].

Escherichia coli was the most frequent bacteria isolated in our patients $(42.42 \%)$ this is in line with most studies on asymptomatic bacteriuria [31-35]. A wide range of other bacteria, however, may be isolated. For elderly subjects and patients managed with intermittent catheterization, E. coli are isolated less frequently in men than women [29,35]. However, the only male patient who had asymptomatic bacteriuria in this study had $E$. coli isolate. Patients with structural or functional abnormalities of the urinary tract, often with foreign material in situ and repeated antimicrobial exposure, frequently have other Enterobacteriaceae and gram-negative organisms, such as Pseudomonas aeruginosa. Gram-positive organisms including Enterococcus spp. and coagulase-negative Staphylococcus other than Staphylococcus saprophyticus may be isolated more frequently from patients with asymptomatic compared with symptomatic infection [7]. In Nigeria, among residents of Zaria, Pseudomonas aeruginosa was reported as the predominant isolate causing asymptomatic UTI [36] while among pregnant women in Ibadan, Nigeria, Staphylococcus aureus was the most prevalent isolate causing asymptomatic UTI [37].

Almost all (94.73\%) 18 of 19 patients who had asymptomatic bacteriuria in this study were females, this is keeping with previous studies which reported a much higher prevalence in females due to the nature of their anatomy [12-14] compared to males.

\section{Conclusion}

More than half of participants who had significant growth had asymptomatic bacteriuria, while one-fifth of all patients had significant bacteriuria. Considering this statistics, screening for or treatment of asymptomatic bacteriuria may be recommended in all HIV-infected patients.

\section{Acknowledgements}

The Institute of Human Virology Nigeria provided registration and CD4 counts free to all registered HIV patients used for this study.

\section{REFERENCES}

[1] R. H. Rubin, E. D. Shapiro, V. T. Andriole, R. J. Davis and W. E. Stamm, "Evaluation of New Anti-Infective Drugs for the Treatment of Urinary Tract Infection," Clinical Infectious Diseases, Vol. 15, Suppl. 1, 1992, pp. S216S227. doi:10.1093/clind/15.Supplement_1.S216

[2] R. Colgan, "Asymptomatic Bacteriuria in Adults," American Family Physician, Vol. 74, No. 6, 2006, pp. 985999.

[3] L. E. Nicolle, S. Bradley and R. Colgan, "Infectious Disease Society of America Guidelines for the Diagnosis and Treatment of Asymptomatic Bacteriuria in Adults," Clinical Infectious Diseases, Vol. 40, No. 5, 2005, pp. 643-654. doi:10.1086/427507

[4] J. Sobel and D. Kaye, "Urinary Tract Infections. Principle and Practice of Infectious Disease," 6th Edition, Elsvier Churchhill Livingstone, Philadelphia, 2005.

[5] C. M. Kunin and J. E. De Groot, "Self-Screening for Significant Bacteriuria. Evaluation of Dip-Strip Combination Nitrite/Culture Test," The Journal of American Medical Association, Vol. 231, No. 13, 1975, pp. 1349-1353.

[6] R. D. Mc Nair, "Evaluation of the Centrifugal and GramStain Smear, Urinalysis and Reagent Strip Testing to Detect Asymptomatic Bacteriuria in Obstetric Patients," American Journal of Obstetrics and Gynaecology, Vol. 182, No. 5, 2000, pp. 1076-1079.

[7] E. N. Lindsay, "Asymptomatic Bacteriuria When to Screen and When to Treat," Infectious Disease Clinics of North America, Vol. 17, No. 2, 2003, pp. 367-394.

[8] C. W. Norden and E. H. Kass, "Bacteriuria of Pregnancy-A Critical Appraisal," Annual Review of Medicine, Vol. 19, 1968, pp. 431-470. doi:10.1146/annurev.me.19.020168.002243

[9] J. R. Johnson, P. L. Roberts and W. E. Stamm, "P Fimbriae and Other Virulence Factors in Escherichia coli Urosepsis: Association with Patients' Characteristics," Journal of Infectious Diseases, Vol. 156, No. 1, 1987, pp. 225229.

[10] A. I. M. Hoepelman, M. Van Buren and P. J. Van den Broek, "Bacteriuria in Men Infected with HIV-1 Is Related to Their Immune Status (CD4+ Cell Count)," AIDS, Vol. 6, No. 2, 1992, pp. 179-184.

[11] "US Preventive Services Task Force Guide to Clinical Preventive Services," 2nd Edition, Screening for Asymptomatic Bacteriuria, 1996. http://www.ahcpr.gov/clinic/uspstfix.htm

[12] J. K. Kayima, L. S. Otieno, A. Twahir and E. Njenga, "Asymptomatic Bacteriuria among Diabetics Attending Kenyatta National Hospital," East African Medical Journal, Vol. 73, No. 8, 1996, pp. 524-526.

[13] Y. Kumamoto, T. Tsukamoto, M. Ogihara, K. Ishibashi, 
T. Hirose, et al., "Comparative Studies on Activities of Antimicrobial Agents against Causative Organisms Isolated from Patients with Urinary Tract Infections (2000). I. Susceptibility Distribution," Japanese Journal of Antibiotics, Vol. 57, 2002, pp. 246-274.

[14] P. C. Inyang-Etoh, G. C. Udofia, A. A. A. Alaribe and N. E. Udonwa, "Asymptomatic Bacteriuria in Patients on Antiretroviral Drug Therapy in Calabar," Journal of Medical Sciences, Vol. 9, No. 6, 2009, pp. 270-275. doi:10.3923/jms.2009.270.275

[15] T. P. Flanigan, J. W. Hogan and D. Smith, "Self-Reported Bacterial Infections among Women with or at Risk for Human Immunodeficiency Virus Infection," Clinical Infectious Diseases, Vol. 29, No. 3, 1999, pp. 608-612. doi:10.1086/598641

[16] J. K. Evans, A. McOwen, R. J. Hilman and G. E. Foster, "Incidence of Symptomatic Urinary Tract Infections in HIV Seropositive Patients and Use of Cotrimoxasole as Prophylaxis against Pneumocystics Carina Pneumonia," Genitourinary Medicine, Vol. 71, No. 2, 1995, pp. 120122.

[17] D. Scholes, T. M. Hooton and D. L. Roberts, "Risk Factors for Recurrent Urinary Tract Infection in Young Women," Journal of Infectious Diseases, Vol. 182, No. 4, 2000, pp. 1177-1182. doi:10.1086/315827

[18] B. Foxman and R. R. Frerichs, "Epidemiology of Urinary Tract Infection 1. Diaphragm Use and Sexual Intercourse," American Journal of Public Health, Vol. 75, No. 11, 1985, pp. 1314-1317. doi:10.2105/AJPH.75.11.1314

[19] P. Catherine and N. Marie-Louise, "Asymptomatic Bacteriuria, Important or Not?" The New England Journal of Medicine, Vol. 343, No. 14, 2000, pp. 1037-1039.

[20] T. M. Hooton, D. Scholees, A. E. Stapleton, P. L. Roberts, C. Winter and K. Gupta, "A Prospective Study of Asymptomatic Bacteriuria in Sexually Active Young Women," New England Journal of Medicine, Vol. 343, 2000, pp. 991-997. doi:10.1056/NEJM200010053431402

[21] J. W. Bachman, R. H. Heise, J. M. Naessons and M. G. Timmerman, "A Study of Various Tests to Detect Asymptomatic Urinary Tract Infections in an Obstetric Population," JAMA, Vol. 270, No. 16, 1993, pp. 1971-1974. doi:10.1001/jama.1993.03510160089035

[22] G. G. Zhanel, L. E. Nicolle and G. M. Harding, "Manitoba Diabetic Urinary Infection Study Group. Prevalence of Asymptomatic Bacteriuria and Associated Host Factors in Women with Diabetes Mellitus," Clinical Infectious Diseases, Vol. 21, No. 2, 1995, pp. 316-322. doi:10.1093/clinids/21.2.316

[23] A. Chaudhry, W. J. Stone and J. A. Breyer, "Occurence of Pyuria and Bacteriuria in Asymptomatic Haemodialysis Patients," American Journal of Kidney Diseases, Vol. 21, No. 2, 1993, pp. 180-183.

[24] S. K. Gupta, B. W. Mamlin and C. S. Johnson, "Prevalence of Proteinuria and the Development of Chronic Kidney Disease in HIV-Infected," Clinical Nephrology, Vol. 61, No. 1, 2004, pp. 1-6.

[25] J. Jao, D. Palmer and I. Leus, "Prevalence and Predictors of Proteinuria in HIV-Infected and Uninfected Pregnant Women in Cameroun," Nephrology Dialysis Transplantation, Vol. 26, No. 9, 2011, p. 3051.

[26] J. Ojoo, J. Paul, B. Batchelor, M. Amir, J. Kimari and C. Mwachari, "Bacteriuria in a Cohort of Predominantly HIV1 Seropositive Female Commercial Sex Workers in Nairobi," Journal of Infection, Vol. 33, No. 1, 1996, pp. 3337. doi:10.1016/S0163-4453(96)92719-X

[27] A. M. De Pinto, G. S. Lopes, C. F. Ramos-Filho, R. Santos-Oda, M. P. De Oliveira, M. Halpern, et al., "Urinary Tract Infection in Men with AIDS," Genitourinary Medicine, Vol. 70, No. 1, 1994, pp. 30-34.

[28] O. M. Ibadin, A. Onunu and G. M. Ukoh, "Urinary Tract Infection in Adolescent/Young Adult Nigerians with Acquired Human Immuno Deficiency Disease in Benin City," Journal of Medicine and Biomedical Research, Vol. 5, No. 2, 2006, pp. 55-60.

[29] C. J. Bennett, M. N. Young and H. Darrington, "Difference in Urinary Tract Infections in Male and Female Spinal Cord Injury Patients on Intermittent Catheterization," Paraplegia, Vol. 33, 1995, pp. 69-72. doi:10.1038/sc.1995.17

[30] L. E. Nicolle, J. Bjornson, G. K. Harding and J. A. MacDonell, "Bacteriuria in Elderly Institutionalized Men," New England Journal of Medicine, Vol. 309, 1983, pp. 1420-1425. doi:10.1056/NEJM198312083092304

[31] L. E. Nicolle, W. J. Mayhew and L. Bryan, "Prospective, Randomized Comparison of Therapy and No Therapy for Asymptomatic Bacteriuria in Institutionalized Elderly Women," American Journal of Medicine, Vol. 83, No. 1, 1987, pp. 27-33. doi:10.1016/0002-9343(87)90493-1

[32] C. M. Kunin, R. Deutscher and A. Paquin, "Urinary Tract Infection in School Children: An Epidemiologic, Clinical and Laboratory Study," Medicine (Baltimore), Vol. 43, 1964, pp. 91-130.

[33] A. L. Le Blanc and W. J. McGanity, "The Impact of Bacteriuria in Pregnancy-A Survey of 1300 Pregnant Patients," Biology and Medicine Journal (Paris), Vol. 22, 1964, pp. 336-347.

[34] G. G. Zhanel, L. E. Nicolle and G. M. Harding (Manitoba Diabetic Urinary Infection Study Group), "Prevalence of Asymptomatic Bacteriuria and Associated Host Factors in Women with Diabetes Mellitus," Clinical Infectious Diseases, Vol. 21, No. 2, 1995, pp. 316-322. doi:10.1093/clinids/21.2.316

[35] L. E. Nicolle, "Asymptomatic Bacteriuria in the Elderly," Infectious Disease Clinics of North America, Vol. 11, No. 3, 1997, pp. 647-662. doi:10.1016/S0891-5520(05)70378-0

[36] J. O. Ehinmidu, "Antibiotics Susceptibility Patterns of Urine Bacterial Isolates in Zaria, Nigeria," Tropical Journal of Pharmaceutical Research, Vol. 2, No. 2, 2003, pp. 223-228.

[37] O. Akinloye, D. O. Ogbolu, O. M. Akinloye and O. A. Terry Alli, "Asymptomatic Bacteriuria of Pregnancy in Ibadan, Nigeria: A Re-Assessment," British Journal of Biomedical Science, Vol. 63, No. 3, 2006, pp. 109-112. 